This is a self-archived - parallel published version of this article in the publication archive of the University of Vaasa. It might differ from the original.

\title{
Social media engagement strategy: Investigation of marketing and R\&D interfaces in manufacturing industry
}

Author(s): Chirumalla, Koteshwar; Oghazi, Pejvak; Parida, Vinit

Title: $\quad$ Social media engagement strategy: Investigation of marketing and R\&D interfaces in manufacturing industry

Year: $\quad 2018$

Version: Final draft (post-print, aam)

Copyright (C) 2017 Elsevier Inc.

\section{Please cite the original version:}

Chirumalla, K., Oghazi, P., \& Parida, V. (2018). Social media engagement strategy: Investigation of marketing and R\&D interfaces in manufacturing industry. Industrial Marketing Management, 74, 138-149.

https://doi.org/10.1016/j.indmarman.2017.10.001 
Social media engagement strategy: Investigation of marketing and R\&D interfaces in manufacturing industry

\section{Highlights}

- Insight into the influencing role of social media in facilitating improved marketing and $R \& D$ interfaces in manufacturing industry.

- Step-by-step adoption process of social media engagement strategy for marketing and $\mathrm{R} \& \mathrm{D}$ interface is developed in three phases.

- The three phases in the adoption process are: namely coordination, cooperation, and coproduction.

- The key activities, infrastructure requirements, and potential benefits are described in detail to the three-phase adoption process of social media engagement. 


\title{
Social media engagement strategy: Investigation of marketing and R\&D interfaces in the manufacturing industry
}

\begin{abstract}
Research shows that effective marketing and R\&D interface is pivotal in a company's new product development performance and future competitiveness. The increased popularity of social media promised to enhance interaction, collaboration, and networking between the two functions. However, there is limited knowledge regarding the key activities, infrastructure requirements, and potential benefits of social media in the marketing and R\&D interface. This study aims to advance the current understanding of social media engagement strategies, which facilitates improved marketing and R\&D interfaces and ultimately NPD performance for manufacturing companies. Based on a multiple-case study in two manufacturing companies, this study first presents the role of social media in facilitating improved marketing and $R \& D$ interface within a B2B context. Second, it presents the adoption process of the social media engagement strategy for an evolving marketing and R\&D interface. The adoption process is divided into three phases, namely coordination, cooperation, and coproduction, to provide detailed insights regarding full-scale social media engagement. Taken together, the study provides novel insights into industrial marketing management literature by exemplifying the role of social media and proposing a systematic social engagement strategy for improved marketing and $R \& D$ interface in the manufacturing industry.
\end{abstract}

\section{Keywords}

New product development, marketing-R\&D interface, cross-functional integration, social media, B2B social media, social media engagement, engagement strategy, R\&D-marketing, social media marketing. 


\section{Introduction}

New product development (NPD) is pivotal to companies' long-term survival and growth (Ahmad, Mallick, \& Schroeder, 2013; Geroski \& Machin, 1992). A prominent key success factor for NPD is the ability to closely integrate and build upon competences from many internal functional departments, such as sales, marketing, research and development (R\&D), engineering, finance, production, and aftermarket (Gomes et al., 2003). Specifically, there is a wide consensus that enhanced marketing and R\&D interface are vital to NPD success (Gupta, Raj, \& Wilemon, 1985; Griffin \& Hauser, 1996; Lam \& Chin, 2005; Li \& Chen, 2016; Song \& Song, 2010; Xie, Song, \& Stringfellow, 2003). This is because the marketing function possesses deeper insights into the customer and the market, and R\&D function represents the knowledge, skills, and capabilities to develop innovative product and service offers. Through improved interface between marketing and R\&D, technical and market expertise are effectively combined to achieve the common business goals such as develop novel product design with higher marketability (Fain, Kline, \& Duhovnik, 2011). A harmonious marketing and $R \& D$ interface helps companies to integrate resources, mitigate innovation risks, access new technologies, enter new markets, improve product quality, and reduce uncertainties (Hempelmann \& Engelen, 2015; Yao et al., 2014).

Although positive benefits from interface integration between marketing and $R \& D$ towards innovativeness have been widely recognized (Fain, Kline, \& Duhovnik, 2011; Olson et al., 2001), studies also acknowledge the higher likelihood of conflicts and challenges arising between marketing and R\&D interface (Hernandez \& Lee, 2007) due to the differences in their personality, backgrounds, language, responsibilities, perspectives, and interests (Griffin \& Hauser, 1996; Wang, 1996). Such an integration gap between marketing and $\mathrm{R} \& \mathrm{D}$ is particularly noticeable among technology companies that are involved in business-to-business (B2B) relationships (Fain, Kline, \& Duhovnik, 2011; Saghafi, Gupta \& Sheth, 1990). Such technology companies require better information exchange, collaboration, and integration mechanisms between marketing and R\&D functions, not only outside but also more importantly inside the company to overcome these integration challenges (e.g. Eng \& Ozdemir, 2014; Song, Neely, \& Zhao, 1996; Wiersema, 2013; Yao et al., 2014).

To improve marketing and R\&D interface, prior studies suggest that companies build 
an interactive communication platform for employees so both the marketing and $R \& D$ entities can share information, work progress, and experiences in order to solve problems faster and more effectively (Yao et al., 2014). Moreover, information and communication technology (ICT) appears to be a very effective tool for enhancing new product performance through knowledge creation within marketing and R\&D (Leenders \& Wierenga, 2002; Song \& Song, 2010). It can facilitate communication possibilities between marketing and R\&D, who might otherwise communicate infrequently or not at all. Moenaert et al. (1994) and Song, Neeley \& Zhao (1996) acknowledged that the formalization of interaction structures and procedures between functions serves as an important platform to develop frequent informal interactions and information exchange.

The emerging social media (Kaplan \& Haenlein, 2010) appear to be promising in this context, thus enabling features that can enhance formal and informal interaction, collaboration, and networking, both inside and outside the organization (Bughin, Byers, \& Chui, 2011; Kietzmann et al., 2011). Some benefits associated with social media are related to improving collaborative knowledge creation and exchange between functions and organizations (Chirumalla, 2013, 2016; Jussila, Kärkkäinen, \& Leino, 2012; Moore, Hopkins, \& Raymond, 2013; Voigt \& Ernst, 2010), identifying new business opportunities (Breslauer \& Smith, 2009; Bertoni \& Chirumalla, 2011), creating and sharing customer information and knowledge (Kärkkäinen, Jussila, \& Janhonen, 2011; Roch \& Mosconi, 2016), and collaboratively developing ideas and concepts (Rohmann, Heuschneider, \& Schumann, 2014; Vuori, 2012). However, the existing social media research focuses either on R\&D (Chirumalla, 2013; Kumar, 2013; Piller, Alexander, \& Christoph, 2012; Roch \& Mosconi, 2016; Voigt \& Ernst, 2010) or marketing (Moore, Hopkins, \& Raymond, 2013; Siamagka et al., 2015), but not specifically on the interface between marketing and R\&D in B2B settings. This is one of the salient areas that Wiersema (2013) emphasized within the field of industrial marketing management. In particular, several researchers recognize the need for a framework explaining the adoption of social media engagement strategy (Cawsey \& Rowley, 2016; Guesalaga, 2016; Jussila, Kärkkäinen, \& Leino, 2012; Lau, 2015; Rodriguez \& Peterson, 2012; Stelzner, 2014) for improved marketing and R\&D interface in B2B context (Wiersema, 2013). 
Against this background, the present study aims to advance the current understanding of the social media engagement strategies, which facilitates improved marketing and $R \& D$ interfaces and ultimately NPD performance in manufacturing companies. More specifically, this study contributes in two ways. First, based on the empirical data, this study advances the current understanding of social media adoption for improved marketing and R\&D interface in B2B organizations (e.g. Jussila, Kärkkäinen, \& Aramo-Immonen, 2014; Song \& Song, 2010; Wiersema, 2013; Yao et al., 2014). It particularly contributes to the discussion on industrial marketing management literature in the context of information exchange (e.g. Hempelmann \& Engelen, 2015), integrative mechanisms (e.g. Lu \& Yang, 2004; Song, Neely, \& Zhao, 1996), and the role of ICT (e.g. Leenders \& Wierenga, 2002; Yao et al., 2014) in marketing and R\&D interfaces. Second, insights into the adoption process of social media engagement strategy for marketing and R\&D interface are developed and explained in three phases (e.g. Song and Song, 2010; Wiersema, 2013; Yao et al., 2014). The proposed three-phase adoption process contributes to the discussion on social media engagement strategy (e.g. Cawsey \& Rowley, 2016; Jussila, Kärkkäinen, \& Leino, 2012; Lau, 2015) and B2B industrial marketing (Wiersema, 2013), especially concerning key social media activities and its infrastructure requirements.

This paper is organized as follows: Section 2 introduces the review of the existing literature on marketing and R\&D interface and social media engagement strategies. Section 3 describes the research methodology, and Section 4 presents the findings of the empirical analysis. Section 5 discusses the implications of the study related to the theory and practice and concludes with limitations and plans for further research.

\section{Theoretical Background}

\subsection{Marketing and R\&D interface}

Improved interaction between marketing and $R \& D$ plays a prominent role in the quality of the end product as well as improved time to market (Gomes et al., 2003). Marketing research provides insights into customers' unsolved problems and latent needs, assesses their reactions to product concepts and features, and helps $R \& D$ engineers in the generation and evaluation 
of new product ideas (Micu et al., 2012). Companies with successful marketing and R\&D interface are capable of effectively analyzing customer needs and requirements, generating and screening new ideas, developing new products according to market needs, and reviewing test market results (Griffin \& Hauser, 1996). Thorough introduction of formalized organizational routines and structures improves the quality and quantity of information exchanged between marketing and R\&D during the NPD process (Song, Neely, \& Zhao, 1996).

Hempelmann \& Engelen (2015) found that information exchange between marketing and $R \& D$ in the new product development process varies over different development stages, such as during the early-stage (idea generation, concept development, business assessment) and late-stage (prototype development, process design, production, and market introduction) periods. Accordingly, the information exchange between marketing and R\&D in the early stage include customers' preferences and product needs, potential customer actions, and potential competitors' actions. The information exchange between marketing and R\&D in the late stage include product specificities and technical attributes, results of product testing and customer trials, and marketing and launch strategy. Song \& Song (2010) identified four key components for the interface integration: joint problem solving, relationship building, information and knowledge sharing, and collaborative communication. Similarly, Rein (2004) described the product innovation process in a global company through fostered synergy between marketing and R\&D at both the early and late stages of the process. At the early stage, marketing and $R \& D$ needed to work together to clarify the market requirements in the marketing plan in order to develop a technical strategy that responded to the market requirements. At the late stage, the functional teams needed to work together to formulate the value messages and use them to market the products. However, prior studies have generally not taken an evolutionary view on the marketing and R\&D engagement.

Moreover, detailed accounts of what kind of activities are central for marketing and R\&D engagement can be important to understand. Lu \& Yang (2004) identified diverse integration activities, divided into four categories: marketing is involved with $R \& D$, marketing provides information to $R \& D, R \& D$ is involved with marketing, and $R \& D$ provides information to marketing. The marketing input in the $R \& D$ process is intended to 
avoid getting a task wrong, rather than attempting to get it right from the beginning. This means the input is intended to (re-)focus the attention of the R\&D staff (Becker \& Lillemark, 2006). Other studies recognize the importance of improved communication (Fain, Kline, \& Duhovnik, 2011; Griffin \& Hauser, 1996; Song, Neeley, \& Zhao, 1996), coordination (Song, Neeley, \& Zhao, 1996), collaboration (Gomes et al., 2003; Jassawalla \& Sashittal, 1997; Leenders \& Wierenga, 2008), and cooperation (Fain \& Wagner, 2014; Leenders \& Wierenga, 2008; Micu, 2012; Olson et al., 2001) for improved marketing and R\&D interface. Gupta \& Wilemon (1988) found that marketing and R\&D cooperation was highest in settings in which organizational practices were conducive to cooperation and $R \& D$ perceived marketing input as credible. Petruska (2004) showed that the stronger the interaction, the more cooperative the participants' behavior and attitudes from two functions were. Furthermore, some researchers also stressed the significant role of joint problem solving, strategic partnerships, and systemic approach linkage for the better interface integration and NPD performance (Fotiadis, 2006; Micu 2012; Wang, 1996). Thus, investigation into how the marketing and R\&D interface can be improved over time with a clearly defined set of activities, infrastructure, and benefits can provide critical insights into achieving business success.

\subsection{Social media engagement strategies: Adoption process}

Social media is defined as "a group of internet-based applications that build on the ideological and technological foundations of Web 2.0 and that allow the creation and exchange of user generated content" (Kaplan \& Haenlein, 2010, p.65). The term "Web 2.0" describes the set of new principles and technology development trends that collectively form the basis for the next generation of the Internet which is characterized by user participation, openness, and network effects (Musser \& O’Reilly, 2006). An essential part of social media is the creation of user-generated content, which collaboratively harnesses the collective intelligence of the individual users and leverages network effects (Scherp, Schwagereit, \& Ireson, 2009). Huang et al. (2010) discussed how social media can drive innovation in organizations by fostering the emergence of informal networks, weak ties, boundary spanners, and social capital through enhancing knowledge sharing and transfer.

Considering the potential opportunities of social media tools, many organizations 
have moved away from traditional marketing methods to social media marketing (Ananda, Hernandez-Garcia, \& Lamberti, 2016). Constantinides \& Fountain (2008) and Lehtimäki (2009) proposed a classification based on the use of various social media tools as marketing channels. These include blogs, social networks, content communities, forum/bulletin boards, content aggregators, and virtual worlds. Social media in B2B has a positive relationship with sales processes (i.e. creating opportunities and relationship management) and performance (Rodriguez, Peterson, \& Krishnan, 2012). Although the benefits of applying social media in $\mathrm{B} 2 \mathrm{~B}$ has been recognized as positive, there are challenges that negatively influence the perceptions of the usefulness of social media in B2B organizations: reputational risks and legal issues, lack of staff knowledge/training, senior managers' lack of support, and reluctance to lose control of the brand (Siamagka et al., 2015). Michaelidou, Siamagka, \& Christodoulides (2011) identified several barriers to social networking site usage in B2B organizations, including uncertainty in using social networking sites to achieve objectives, employees' lack of knowledge about sites, and higher cost of investments. Thus, considering specifically how social media may facilitate improved marketing and R\&D interface in the B2B company context holds high value for the present study.

The existing social media research focuses either on R\&D (Chirumalla, 2013; Kumar, 2013; Piller, Alexander, \& Christoph, 2012; Roch \& Mosconi, 2016; Rohmann, Heuschneider, \& Schumann, 2014; Voigt \& Ernst, 2010) or marketing (Moore, Hopkins, \& Raymond, 2013; Siamagka et al., 2015), but not on the interface between marketing and R\&D in a B2B setting. Rohmann, Heuschneider, \& Schumann (2014) indicated that previous studies on social media have mostly focused on the early stage of the NPD process. Internally, social media helped organizations to involve functional departments with direct contact with customers in product development in order to collaboratively develop ideas and concepts (Rohmann, Heuschneider, \& Schumann, 2014), thus bridging boundaries between functions and enhancing community building (Vuori, 2012). Vuori (2012) found that internally social media is also used for internal communication, knowledge transfer, reaching personnel, and conducting internal idea crowdsourcing. Blogs are commonly used in the ideation phase to identify the needs and preferences of customers, to discover new trends, and to generate attention before the market launch of a new product (Kaplan \& Haenlein, 2010). 
In the late stages, social media tools are used for tasks surrounding the launch of the product and the customer service support purposes (Rohmann, Heuschneider, \& Schumann, 2014). Furthermore, the tools allowed companies to perform R\&D, marketing, and sales tasks (Roch \& Mosconi, 2016). However, researchers emphasized that the current literature does not present a complete picture of the application areas for social media in NPD (Rohmann, Heuschneider, \& Schumann, 2014; Roch \& Mosconi, 2016).

Song \& Song (2010) suggested that communication technologies and decision-aiding technologies are used to reduce the negative impact of physical separation, goal incongruity, and cultural differences on marketing and $R \& D$ interface integration. There are several factors that influence the successful use of social media in new product development (Kumar, 2013), including the selection of the right IT tool, alignment of new product development processes, restructuring of the product development organization, hands-on training for product development managers on the use of social media, organizational change management, and the culture of the organization to drive decisions based on input from social media.

Researchers and practitioners are using social media engagement strategy as a way to systematically address various factors related to the social media adoption process (Cawsey \& Rowley, 2016; Jussila, Kärkkäinen, \& Leino, 2012; Lacoste, 2016; Spil, Effing, \& Both, 2016). The concept at the meta-level is defined as a form of social, interactive behavior, which is characterized as a transient state occurring within broader relevant engagement processes developed over time (Brodie et al., 2011, p. 254). Previous research has proposed numerous frameworks, dimensions, or evaluation practices that seem to be linked to the engagement states and processes. For instance, Marcos-Cuevas et al. (2016) presented value cocreation practices divided into three overarching categories: linking (i.e. practices related to mobilizing social connections and networks such as co-ideation, co-valuation, and codiagnosing), materializing (i.e. operational practices related to the production of a value cocreating offering such as co-testing, co-design, and co-launching), and institutionalizing (i.e. organizational practices related to the design of institutions and structures to capture and retain value created such as embedding). These practices can help to attain "sustained purposeful engagement" between actors in value cocreation, thus providing related 
stakeholders with an equal opportunity to contribute ideas, raise questions, and allow others to respond to these ideas and questions (Bryer, 2013).

Rodriguez \& Peterson (2012) categorized social customer relationship management in B2B marketing into four stages, namely content, conversations, engagement (friends, partners, collaborators), and meaningful relationships. Accordingly, customer relationship management initially starts with the need to attract users by providing compelling content through online communities, webinars, and blogs, thereby creating a platform for conversations on the content, which results in engagement with the users and in turn creates deeper, meaningful relationships with users and the community. Cawsey \& Rowley (2016) proposed a framework with six components of a social media strategy: monitoring and listening, empowering and engaging employees, creating compelling content, stimulating electronic word of mouth, evaluating and selecting channels, and enhancing brand presence through integrating social media. Jussila, Kärkkäinen, \& Leino (2012) categorized social media use of interaction forms in the B2B innovation process into five types: without direct interaction, one-way interaction, two-way interaction, community-interaction, and user toolkit-supported interaction. However, the current literature does not provide framework with detailed insights into key activities, infrastructure requirements, and benefits, which are areas the present study explores.

Table 1. Summary of the key engagement strategies relevant to the focus of the study

\begin{tabular}{|l|l|l|}
\hline Authors & Dimensions or adoption process steps & Focus of the study \\
\hline $\begin{array}{l}\text { Rodriguez \& } \\
\text { Peterson (2012) }\end{array}$ & $\begin{array}{l}\text { Content, conversations, engagement, and } \\
\text { meaningful relationships }\end{array}$ & $\begin{array}{l}\text { Customer relationship } \\
\text { management in marketing }\end{array}$ \\
\hline Lacoste (2016) & $\begin{array}{l}\text { Connection (preparing and initiating), } \\
\text { interaction, satisfaction, retention, } \\
\text { commitment, advocacy, and engagement }\end{array}$ & $\begin{array}{l}\text { Building and developing } \\
\text { relationships }\end{array}$ \\
\hline $\begin{array}{l}\text { Cawsey \& Rowley } \\
(2016)\end{array}$ & $\begin{array}{l}\text { Monitoring and listening, empowering } \\
\text { and engaging employees, creating } \\
\text { compelling content, stimulating electronic }\end{array}$ & $\begin{array}{l}\text { Brand building and } \\
\text { management }\end{array}$ \\
\hline
\end{tabular}




\begin{tabular}{|l|l|l|}
\hline & $\begin{array}{l}\text { word of mouth, evaluating and selecting } \\
\text { channels, and enhancing brand presence } \\
\text { through integrating social media }\end{array}$ & \\
\hline $\begin{array}{l}\text { Jussila, } \\
\text { Kärkkäinen, \& }\end{array}$ & $\begin{array}{l}\text { No direct interaction, one-way interaction, } \\
\text { two-way interaction, community- } \\
\text { interaction, and user toolkit }\end{array}$ & $\begin{array}{l}\text { B2B customer interaction } \\
\text { forms }\end{array}$ \\
\hline $\begin{array}{l}\text { Spil, Effing, \& } \\
\text { Both (2016) }\end{array}$ & $\begin{array}{l}\text { Engagement (goals, channels, target } \\
\text { groups, content), evaluation (ROI, } \\
\text { monitoring, tools, and listening), and } \\
\text { enabling (partners, capacity, resources, } \\
\text { policies) }\end{array}$ & $\begin{array}{l}\text { Design, develop, and } \\
\text { evaluate social media } \\
\text { strategy }\end{array}$ \\
\hline $\begin{array}{l}\text { Marcos-Cuevas et } \\
\text { al. (2016) }\end{array}$ & $\begin{array}{l}\text { Linking, materializing, and } \\
\text { institutionalizing }\end{array}$ & Value co-creation \\
\hline
\end{tabular}

\section{Method}

\subsection{Research approach}

Given the research focus on advancing the current understanding of social media adoption for improved marketing and R\&D interface, a qualitative approach was deemed appropriate for such a phenomenon, which is multifaceted and context bound. Through qualitative case studies, researchers can develop and offer detailed insights and uncover substantial complexity reflecting both organizational and individual processes (Eisenhardt \& Graebner, 2007; Miles \& Hubermann, 1994; Yin, 2009). This approach is especially appropriate, given the limited knowledge about social media engagement strategy in marketing and R\&D interface. Thus, researchers in the business domain have used the case study research method in studying real business situations, issues, and challenges (Eriksson \& Kovalainen, 2008). A case study was selected by means of purposeful sampling, which provides a powerful, rational means to select information-rich cases for in-depth study (Patton, 2002).

\subsection{Case companies}

The multiple case study was performed on two industrial manufacturing companies that are positioned in an aerospace supply chain. The companies were chosen for three reasons. First, 
the companies placed strong emphasis on pursuing NPD through improving marketing and R\&D interface. Second, case companies had adopted social media, which provided a suitable opportunity to capture their learning through their experiences in marketing and $R \& D$ interfaces. Third, the case companies presented possibilities to collect rich data on both sides of the interfaces, such as marketing and $R \& D$ functions.

Case company $\mathrm{A}$ is a process technology supplier, providing both machining tool hardware and the application software. The company strives to identify constantly both the unspoken and outspoken needs of the customer and convert them into new product and service offerings through marketing and R\&D interface. The communication modes in the interface processes usually vary in different stages, including face-to-face meetings, e-mails, phone calls, workshops, customer interactions, training workshops, physical visits, informal communications, and internal discussions. Market needs and business opportunities are gathered in different ways within the company. The front-line employees (i.e. marketing, sales, technicians) usually visit the customer sites at which their products have been used. They exchange this knowledge internally in the form of documents, films, and meetings. Market needs are also gathered from business intelligence, surveys, complaint analysis, competitor benchmarking, annual strategy meetings with product specialists, and other experiences within the company, including global sales units, in the form of films or documents. This company has experience using diverse social media platforms (e.g. for application $\mathrm{R} \& \mathrm{D}$, marketing processes, and best practices), specific project spaces based on Microsoft solutions, blogs, and Facebook. The study was conducted to obtain generic data on the company's NPD and service development processes, in order to define scenarios for internal cooperation in marketing and $\mathrm{R} \& \mathrm{D}$ interfaces using social media.

Company B is an aero-engine component manufacturer, offering aero-engine components and additional maintenance services to aircraft engine manufacturers and airlines. The component development requires close collaboration with the original equipment manufacturer (OEM) in order to handle the several interfaces each component has with other parts of the engine. This collaboration is described as a risk- and revenue-sharing partnership rather than a customer-supplier relationship to share development costs and risks. A risk- and revenue-sharing partnership brings new demands and requirements on 
information management concerning different access and security levels, with many more boundaries between organizations and inherent communication difficulties. Internally, they communicate mainly through face-to-face meetings, informal meetings, phone and email conversations, phone/web conferencing, etc. The market needs are often presented by the airliners to engine manufacturers and to the component manufacturer. Internally, in the early phases, decisions are made through a series of physical meetings focused on commercial, technical, manufacturability, and quality issues, during which inputs from design, business, and production functions are considered. Similar to Company A, there is a significant amount of work in the early conceptual phases involving work iterations or loops. The reports on these iterations are either documented internally in a project-related database or in diary notes, meeting notes, and PowerPoint presentations. The company deployed social media capabilities, such as blogs, wikis, and social networking based on Microsoft SharePoint, to enhance internal collaboration and knowledge sharing. The case study was conducted to elucidate how cross-functional teams use various existing IT systems and social media capabilities in their routine activities, especially in the interface between marketing and R\&D. The goal was to identify the potential opportunities and challenges working with social media in the NPD process.

\subsection{Data collection and analysis}

Data was collected through semi-structured interviews, observations, focus groups meetings, and documentation. Interviewing is considered a primary means for collecting case study information (Yin, 2009), as it facilitates the exploration of the real-life phenomenon from stakeholders' perspectives (Kvale, 1996; Lofland et al., 2005). With almost an equal split between the case companies, a total of 38 interviews, 6 focus group meetings, and 4 observation sessions were performed. The interviewees represent people in a wide range of positions in the company hierarchy (e.g., managers, director, specialists, team leaders, project leaders, process supervisors, system supervisors, engineers, designers, and technicians) and activities (e.g., business development, marketing, R\&D, application development, product planning, simulations, engineering, method development, customer support, manufacturing, serial production, quality, product support, maintenance, and IT 
architect and services). The interviews were recorded, transcribed, and reviewed by the respondents for accuracy, and notes were collected from other meetings. Focus group discussions were conducted to access broad ranges of opinions with open-ended questions (Mack et al., 2005), acquiring a complete picture on how social media can affect marketing and $R \& D$ interface and identifying solutions that marketing and $R \& D$ interface process needs. Observation sessions (Eisenhardt \& Graebner, 2007) were performed on different occasions at the case companies in order to understand the issues surrounding various ICT systems from a holistic perspective and provided insights related to the daily activities of the marketing and R\&D team, including their interaction with related systems. During this period, field notes were collected, and several organizational documents were reviewed. Interview transcriptions, focus group notes, field notes, and collected documents were analyzed using spreadsheets with a pattern-matching technique (Yin, 2009) to identify the topics connected to the purpose of the study. Several themes were then drawn out for further analysis based on the emerging patterns related to internal social media adoption, traditional IT systems, potential opportunities, challenges, interface between marketing and R\&D, interface processes, and engagement strategy. These themes were further analyzed to draw conclusions, iterating between problems, theory, and empirical data.

\section{Results}

The empirical results are presented as follows. First, the role of social media in facilitating improved marketing and R\&D interface is explained using four key activities from the early and later stages of the development. Second, the social media engagement strategy to support and improve marketing and R\&D interface is proposed and explained.

\subsection{Social media for facilitating improved marketing and $R \& D$ interface}

The empirical analysis identified four key activities in which social media can facilitate improved marketing and R\&D interface. These activities include the ability to: 1) identify and communicate new business opportunities, 2) find the right competencies and compose cross-functional teams, 3) capture and discuss the rationale for customer needs and design intent, and 4) collect and use customer feedback and product performance. The above 
activities represent both early and later stages of development (Hempelmann \& Engelen, 2015), in which the first two activities occur in the early stage, the third activity belongs to both stages, and the fourth activity belongs to the later stage.

\subsubsection{Identify and communicate new business opportunities}

Developing seamless value offerings requires deeper understanding of customer preferences and needs between marketing and R\&D functions. Front-line personnel exchange this knowledge via informal interactions, email, and reports, but this limits their ability to reach wider audiences and identify potential business opportunities to initiate a new project. One of the interviewed process managers explains one such example:

"Once, one of our customers was trying to optimize a turbine blade machining process using some of our tools in his low-power machine. After a while, a technician visited his shop floor and noticed that he had been able to get significant process improvements by radically modifying the machining settings in a way we did not even consider in the beginning. He made a video, which was stored in a local database. However, several months passed before he could share what he had found with one of our product development engineers, and it happened by chance at the margins of a training event. The movie has been further analyzed and provided relevant knowledge for the next tools' development."

This example clearly illustrates that companies are not capitalizing on the wide array of knowledge available to them, missing opportunities to bring different knowledge domains together to formulate creative responses and innovative solutions to customer needs. In one of the focus group meetings, one R\&D director suggested the following:

"I think we have to capture customer activities and problems in machining and make it visible to a larger audience in a lighter way. That will show a lot of potential for the future market."

According to the informant, such a practice could make the information available to different application centers and the marketing function, which could help R\&D to go through the initial input from the experts and make the best decision based on the facts.

The case company's early experiences in deploying social media tools such as blogs 
and wikis revealed that these tools, with their interactive user-authored pages and conversational formats, significantly lower the threshold for documenting personal insights and experiential knowledge, giving front-line employees a forum to define customer impressions and ideas and making them available to R\&D teams and other functions. Furthermore, they allow information to be presented in multiple formats, such as image, video, or audio, which can help capture rich contextual information. One experienced process manager told the author the following:

"Blogs and wikis are powerful tools to... bring the discussion into more open and shared space, where other persons can address relevant questions, give comments, and follow more open dialogues, and moreover we can increase the network around certain areas/issues."

Such functionalities can enable marketing and R\&D personnel to discuss dynamic customer needs both within and between their teams, generate ideas and concepts, and take initiative for a new project to address customers' unsolved problems and latent needs or, if possible, enter a new market.

\subsubsection{Find the right competencies and compose cross-functional teams}

The case analysis highlighted the difficulty of identifying the right people with relevant competences to compose effective cross-functional teams in the early stage of development. Currently, the project team recruiting process is more dependent on people contacts and personal networks than on the information contained in the IT system. The case companies stressed that they have the right knowledge and competencies to address different customer demands, but they are struggling to utilize this knowledge to address customer needs. One R\&D engineer stated:

"We have different levels of knowledge and experiences from different experts around the world.... It is very difficult to find and allocate people to each project, especially in the context of cross-functional teams."

As the knowledge and expertise are geographically distributed, it is difficult to discover people "who know" and people "who may help" with a specific problem outside the usual network of connections, as outlined by one of the interviewed IT managers: 
"Our group also has a naval department. Once it developed an innovative and heavily publicized engine model, which broke down on its first public trial. Then, at the annual corporate Christmas party, a group of naval engineers met experts from our aerospace division and started to discuss the incident. Plenty of issues that were not properly considered during its design popped up. They went back to work, made the modifications, and it worked. I think that's a great story."

In the above example, expertise was shared in an informal, face-to-face manner at the annual meeting, which calls for new solutions that could help practitioners, such as marketing and R\&D personnel, to share their complex problems in an open shared space. The same informant on the above problem conveys a similar view:

"I think we need these Christmas parties online [here I interpret that this informant is using Christmas parties as a metaphor for informal meetings], where you can easily send out questions, and the community may give you feedback."

With social media tools, information is more easily searchable, up-to-date, accurate, and verifiable. At the case company, the implementation of personal sites has offered an alternative to the structured competence database, as people work to keep their profiles consistent and up to date. An IT manager noted:

"Now we have a personal page, where people are free to update information about themselves. I see that many users are taking time to add information and to make themselves visible throughout the company."

Accordingly, personal sites can provide better data for staffing a team than traditional, topdown competence databases, which are difficult to populate and maintain. An IT architect saw "great potential in social software when it comes to searching for the right competencies and finding the right people.... Now people could search for the profiles outside of the company, for instance, through the integration with social networking sites such as LinkedIn."

\subsubsection{Capture and discuss the rationale for customer needs and design intent}

The empirical study highlighted the need for a more practical approach to capturing and storing the rationale for the given customer needs and design. Most of this information is 
currently scattered throughout a collection of documents, such as presentation files, Excel sheets, and personal notes, as well as marketers' and designers' memories. Thus, keeping the traceability of customer needs throughout the process is difficult. Since there are so many passages, some information may be lost, or it may even be transformed along the way, depending on how different people intend it to be designed. For instance, if a key person leaves the job, it is quite difficult for others to step in and fulfil customer needs. Furthermore, the case analysis highlighted that domain-specific databases are access protected outside a given project or function; in addition, they contain few explanations of the processes behind the decisions. In one of the observation periods, one senior design leader described the search problem as follows:

"The biggest limitation is if you work, for example, on product X, and you work with that for 10 years and build a lot of experience. Then you switch to product $Y$, and you are now disqualified to look at $X$ documents. You are not able to search your old experience that you built up for 10 years."

"We have a very rigid system to get access to, and it is unclear sometimes who has access to it."

In this regard, social media functionalities can support practitioners in creating easily shared workspaces. Blogs prove useful for document ideas, insights, and early informal feedback from marketing, R\&D, and related stakeholders on customer needs, potential competitors' actions, marketing testing, and new design solutions. Wikis may be used in addition to the existing project repositories to collect and provide access to the underlying rationale regarding a solution in case the original documentation is secured.

The networking capabilities and feedback mechanisms offered by blogs and wikis, such as commenting, rating, and voting, also facilitate more participation by distributed stakeholders in marketing and $\mathrm{R} \& \mathrm{D}$, although participation in these systems has been very inconsistent. As one of the process managers expressed:

"People may have very personal ideas on how an engine mount or a boss should be designed. Being able to formalize this unstructured information would mean that very early other people could say: "this is good" or "this is completely wrong" ... If we can use these social functionalities properly, the discussion could rise much earlier 
than it happens today.... We could keep track of the context in which information is generated."

\subsubsection{Collect and use customer feedback and product performance}

To assess the NPD performance and efficiency, it is essential to follow up and monitor the product performance during the initial stages of product use. In current practice, customers typically report their non-conformances, improvement ideas, and product performance results in their specific databases. Such practices are not efficient mechanisms for marketing, and R\&D functions to continuously give input to each other's activities. Providing means to develop ties with the front-line employees who can offer customers' insights and experiences of the product can enhance the capability of the R\&D team to understand how to add value to the customer and identify much earlier the right problem-solving strategy to pursue.

The case company's blog implementation has demonstrated that blogs serve as easy, effective tools for archiving and sharing experiences. One project informant highlighted the benefits of such open documentation as follows:

"Blogs spread the information more in the projects, so respective stakeholders know that first part went to workshop, manufacturing sequences and milestones, etc. It's more about making sure that the respective team is getting the feedback about the product in later stages of product development, etc."

Similarly, ongoing learning videos from customers help explain and demonstrate the root cause of a problem visually and in greater detail. During the observations, one design leader explained the benefit of using video sharing for providing experience feedback to R\&D and marketing functions at a component level:

"Videos are good... easier to go through and to get the clear overview of what is specific to each component."

Furthermore, feedback mechanisms (i.e. likes, ratings, number of views, comments, or bookmarks) can help both marketing and $R \& D$ raise awareness of particularly popular topics, which can influence the design of the product and service. 


\subsection{Social media engagement strategy to improve marketing and $R \& D$ interface}

Although social media play a significant role in supporting marketing and R\&D interface both in early and late stages, our analysis identified a number of internal barriers for the wide adoption of social media. These include the lack of a holistic picture with social media engagement, the need for active participation to create vibrant shared content over time, the challenges of validating knowledge quality and reliability, and the lack of systematic integration between marketing and R\&D functional activities. These barriers call for a planned strategic engagement approach to support the internal marketing and R\&D interface through social media. Accordingly, the following courses of action should be implemented: (1) Companies should define the objective of an engagement strategy and implement social media tools in phases to build the better shared content in the interface, (2) The diverse activities must be understood and integrated into regular business processes to view it as part of mainstream work, (3) Companies should identify ways to utilize social media infrastructure in a series of phases for improving the interface, and (4) The benefits of utilizing social media engagement in each phase need to be specific and clearer for companies.

These insights drive case companies to deploy and progress through social media engagement strategy by capitalizing on the enabling capabilities of social media. The evolution process of engagement in the marketing and R\&D interface should occur through a series of phases rather than an ad-hoc single-phase approach. Hence, companies realize the need to take a more strategic approach to achieve the successful deployment and engagement efficiency in the marketing and R\&D interface. Through empirical case and review of theory on the marketing and R\&D interface, this study proposes three phases: coordination, cooperation, and coproduction. Figure 1 and Table 2 explain the three phases, their detailed step-by-step processes, and key activities for the social media engagement strategy for marketing and R\&D interface.

Figure 1. The three-phase adoption process of social media engagement strategy for marketing and R\&D interfaces. 


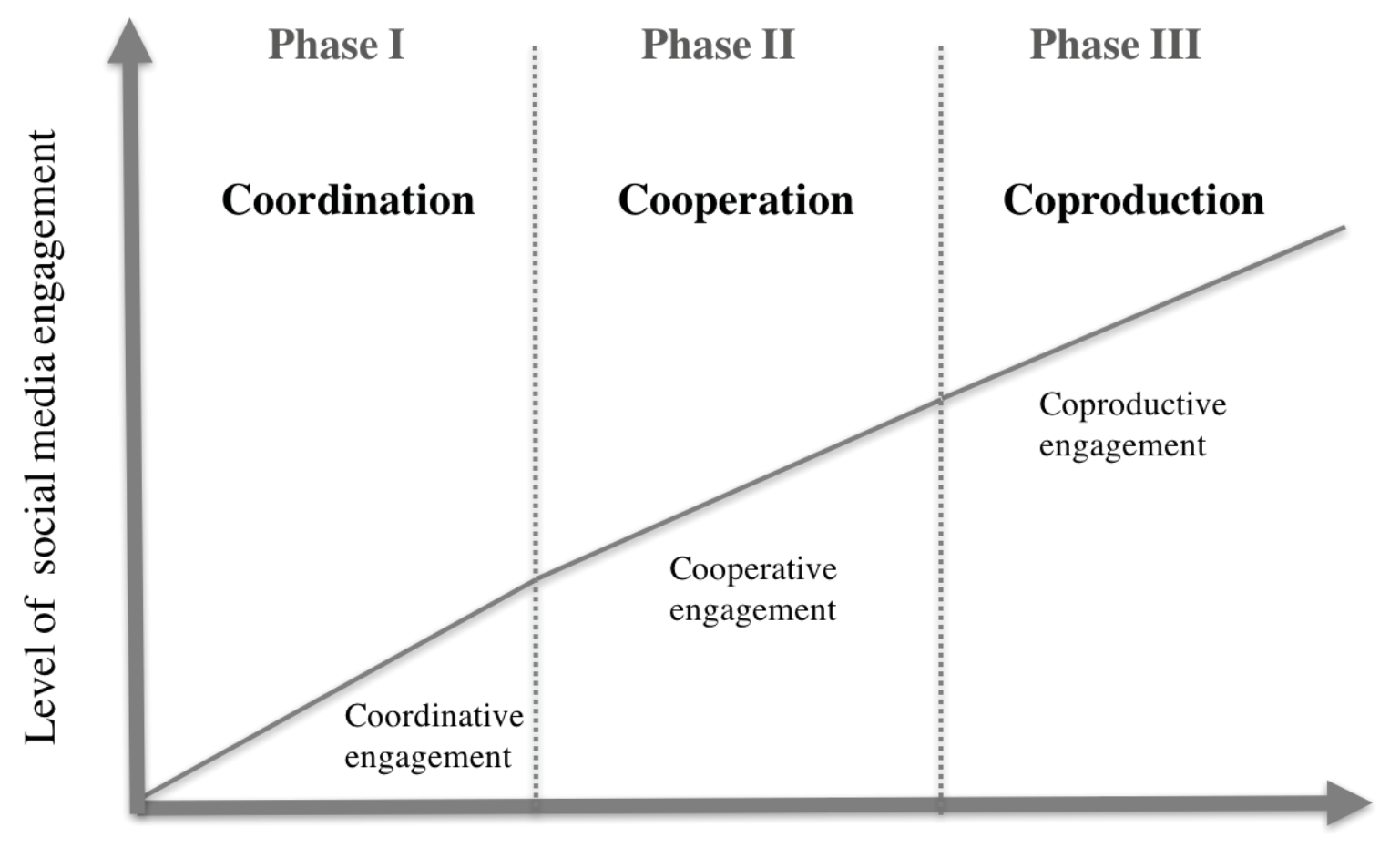

\section{Level of interface integration}

\subsubsection{Phase I: Coordination}

The first social media engagement phase is called coordination, which aims to establish integration between marketing and $\mathrm{R} \& \mathrm{D}$ functions in which each function can provide relevant information to each other to accomplish a collective set of tasks. For instance, in the early stages, marketing provides information to $R \& D$ on customer preferences of new products, and potential customers' and competitors' actions. In the late stages, marketing shares product testing results and customers' feedback with $R \& D$. On the other hand, $R \& D$, in the late stages, provides information to marketing on new product design, technical feasibility analysis, and prototype development and testing.

While explaining the importance of coordination, one of the R\&D engineers explains the problem in the current practice as follows:

"The flow of information from the customer to the marketing to the $R \& D$ and viceversa is, in fact, broken down into several pieces with the involvement of several intermediaries... The information may be lost due to different interpretation by the 
involved actors in the process."

With social media, the key objective in this phase is to synchronise engagement activities in a systematic way to achieve efficient one-way engagement between marketing and R\&D functions. This means that one functional organization, e.g. marketing, could take a social media engagement activity independently in relation to another function, while R\&D function can attempt to synchronise its activities to fulfil the goals set by marketing. The study identified following social media engagement activities that could help companies to establish an efficient one-way coordination between marketing and R\&D interface. Based on the analysis of the case companies, we find three key activities that are central to using social media engagement for marketing and R\&D interface at this phase: 1) policy and norm development, 2) the appropriate engagement level, and 3) establishment of a social platform.

1. Policy and norm development: Empirical analysis shows that companies can start their social media engagement process by mapping the needs, expectations, and goals with the social presence in the interface between marketing and R\&D. During this coordination phase, engagement is promoted through marketing and R\&D functions by synchronizing their activities towards goal fulfilment and collectively defining social media's policy (norms, rules, and guidelines). This would also include the selection of social media tools, process flow of content, monitoring, and training plans. Based on the developed policy, both functions initiate a competence profile social site within the interface. The competence profile includes all relevant details of the marketing and R\&D teams, their competences or expertise, and their past and ongoing project experiences.

2. The appropriate engagement level: Observations suggest that, after establishing a policy and profile, marketing and $R \& D$ functions need to identify a range of products and services in which social engagement is required in the interface. This could help to promote the appropriate engagement efforts with the suitable resources in the early stages. Once the right resources and activities are established, with the use of social media platform, an internal customer or market knowledge base is created by marketing, including market or industry trends, weak signals, and customer preferences to share with R\&D. At the same time, based on marketing's knowledge base, R\&D could align its 
internal activities and provide the necessary input and feedback to marketing. Such a systematic synchronisation of activities establishes a solid foundation to the coordinated engagement in the early phases.

3. Establishment of a social platform: Finally, analysis found that marketing and R\&D can continue their coordination engagement at a higher maturity level. Through establishing the social media platform, $R \& D$ provides information to the marketing on new product or service design ideas, prototyping of construction and testing results, and rationale for design decisions during development. Similarly, marketing shares its testing results, customer feedback, or improvement ideas from the customer with R\&D.

With the above systematic adoption of social media engagement, marketing and R\&D can achieve considerable synchronisation in their interface activities, achieving a low level of interdependency in their coordination. Our empirical observation and discussion with companies show that these activities initiate trust and establish a new relationship to understand each other's goals, issues, and preferences. The outcome of this adoption phase is the establishment of a weak tie between marketing and R\&D and a low degree of maturity in social media engagement. Additionally, R\&D achieves customer or market orientation in its activities, whereas marketing benefits from receiving constant feedback and learning lessons from the R\&D. We also observed that such benefits were constrained by few challenges. For example, achieving a good coordinative social engagement requires dedicated planning and commitment from marketing and R\&D functions, as it requires them to move away from their traditional comfort zones and change their mindset in the prioritization of tasks.

Our empirical analysis revealed that, in this phase, the infrastructure for social media should support marketing and R\&D functions to provide input and information to each other. Hence, the traditional marketing and R\&D systems can still be used, but it should complement social media functions such as blogs, microblogs, wikis, LinkedIn or Facebook pages, or YouTube. For instance, marketing could complement its systems with a blog to share customer preferences, ideas, and best practices with the R\&D. The R\&D function begins to use Facebook or LinkedIn to build and manage competence profiles within its function. Furthermore, microblogs can be used by marketing and R\&D to notify customer 
problems, to discuss product related questions, and to inform new product and service designs and its features. Video clips can be shared through YouTube or other similar platforms to share success stories, customer insights, and results from testing and product performance results. Wikis are useful as they codify the rationale for design decisions to track down the history from the customer needs as well as to develop target customers' or the market's knowledge base. One of the experienced managers in the focus group meeting acknowledged the role of social media for the coordination as follows:

“...the major difficulties during product development were that we are not using social networking tools as much as we can. We are not utilizing forums, blogs, and wikis to a great extent.... We need to get a level where we can support standard enterprise systems with wikis and blogs for coordinating and feeding informal information from the coffee room conversations and functional/personal meetings.

\subsubsection{Phase II: Cooperation}

The second social media engagement phase is called cooperation, which aims to associate marketing and R\&D in which each function can be involved in other activities to share expertise, progress, and resources. The cooperation engagement leads to the establishment of collective actions in the pursuit of common goals (i.e. a common problemsolving activity in which one can depend on the input of the other one). For instance, in the early stages, marketing is involved in R\&D activities to generate and screen new product ideas, set NPD goals and priorities, and find marketable application of R\&D's ideas and technologies. Similarly, R\&D is involved in early-stage marketing activities to analyze customer needs, evaluate new product ideas, set NPD according to the market's needs, and modify products according to marketing's recommendations. On the other hand, in the later stages, marketing is involved with $\mathrm{R} \& \mathrm{D}$ on different reviews and evaluations related to a product's quality and performance, and R\&D is involved with marketing in the commercialization and launch strategy. One of the design informants emphasized the importance of cooperation and need for tools as follows:

"We have to be more involved in the front-line activities than we do today.... should have some better tools for receiving and sharing knowledge generally. But it is the big 
question of how to form these tools more effectively, how to adopt and work with the content in a progressive way with other internal functions than we do now."

With advanced social media, the key objective of this phase is to synergize engagement activities through joint actions in order to achieve an efficient two-way engagement between marketing and R\&D interface. This could help to select the desired interface activities, thereby achieving better interface performance with the better utilisation of resources. Based on the analysis of the case companies, we find three key social media activities that are central to achieving two-way engagement at the marketing and R\&D interfaces: 1) promote communities and incentive monitoring, 2) interactive cooperation mechanism, and 3) cooperative alignment processes.

1. Promote communities and incentive monitoring: Empirical findings show that, for establishing cooperative social media engagement, marketing and $R \& D$ functions can build on their earlier adoption efforts in phase I. More specifically, using social networking tools, the marketing and R\&D functions form specific interface communities or cross-functional teams based on the types of projects, products, and specialised competence areas present. These communities constantly discuss and analyse potential customers' and competitors' actions. To further enhance active participation in these communities, both functions need to define some form of incentive and motive. Based on the progression in activities, marketing and $R \& D$ should plan and perform monitoring meetings on social media to track and analyse the social media content and presence as well as to cope with IPR-related issues.

2. Interactive cooperation mechanism: After the establishment of communities and monitoring, marketing and R\&D functions should select the desired processes from the early stage that need social media engagement. Then each function makes a structured plan to get involved in other processes. Based on this plan, marketing and R\&D integrates social media tools with the existing systems in these processes. One IT informant acknowledged the problem with the existing systems as follows: "I think we locked in too much information by putting them in a documentation system, where over time they become useless. Someone said that those traditional document systems are graveyards, 
and I think they might have a point". One designer engineer acknowledges the benefits of social media in this regard: "Social media can make some significant improvements here, and it can act more or less as an informal collector of different discussions, opinions, expertise, and knowledge about practices." After the integration with the existing systems, to promote two-way engagement, marketing and R\&D should define specific interactive feedback mechanisms (i.e. comments, clicks, rank/rate, likes, shares) that are important to promote interface cooperation and plan dedicated resources to support these mechanisms. After defining the feedback mechanisms, marketing and R\&D can engage in the process of analyzing and evaluating customer needs, modification requests, new product ideas or concepts, NPD goals and priorities, and the NPD schedule. In this way, the ways of giving and receiving feedback in the interface processes is clearly understood by two functions, and hence cooperative engagement is established with mutual consensus.

3. Cooperative alignment processes: Finally, we found that, in the late stages, marketing and R\&D get further involved and integrate each other's processes to approach the joint problem solving through social media engagement. Both functions share and discuss each other's initial testing results, such as product performance testing or customer trials (successful and unsuccessful stories) and ask for feedback in the form of comments or rating, etc. Next, based on the continuous insights and feedback, marketing or R\&D can align with each other's processes for the better fit of commercial interest to the technology and vice versa.

With the above cooperative social engagement activities, marketing and R\&D can achieve a medium level of maturity and interdependency. Marketing and R\&D functions believe that these activities are helpful in the process of achieving shared value and understanding to consider each other's future needs as well as joint problem solving. Furthermore, by enabling many touch points between marketing, $R \& D$, and the customer, social media engagement becomes a primary channel for both functions to reduce uncertainty and risks in development activities. We also found that such benefits can be constrained by few challenges. For example, the involvement of each other's activities might lead to conflict of interest or trade- 
off discussions in the beginning, requiring a good synergy between several functions. Thus, care should be taken to overcome such situations by promoting more successful stories and perceived potential benefits for the interface in the long run.

Our empirical analysis revealed that, during this second phase, the social media infrastructure needs to be matured compared to phase I in terms of activities and the level of intensity. We observed that the engagement shifts from merely providing input (i.e. 1-way engagement) to active participation in the activities to analyse, and giving and receiving feedback (i.e. 2-way engagement). Marketing or R\&D receives feedback on its blog post and begins to understand each other's perceptions on new ideas, improvements, product features, and projects. A microblog is used to trouble shoot, discuss, and learn from customer problems or testing results. Furthermore, the rationale and customer or market information is discussed and analysed on the Wiki and YouTube. The specialized communities are formed on Facebook or LinkedIn for specific products or project types or regions in order to discuss development ideas, goals, and test results.

\subsubsection{Phase III: Coproduction}

The third B2B social media engagement phase is called coproduction, where marketing and $\mathrm{R} \& \mathrm{D}$ are jointly work together to develop and produce the core offering in order to create a unique value. For instance, in early stages, both marketing and R\&D, can work closely to jointly discuss the customer requirements and strategic plans and jointly generate new product ideas and scenarios. In the late stages, they can jointly reflect on the learnings from the testing and market introduction in order to make a continuous renewal in their product and service portfolio. During one of the focus group meetings, two informants expressed the importance of coproduction as follows:

"It is important to identify value-adding opportunities in terms of developing new product and service combinations by observing the customer process cycles in a continuous manner.... An effective knowledge exchange needs to be established by jointly working together to better understand the market demands, adapt the offer to the changing environment, and continuously innovate products." 
"We can provide a lot more than a hardware product, i.e. providing all the functionalities around the engine like manual documentation, education, training, engineering support, maintenance, safety issues etc.... We work collaboratively early, we want to be even earlier, of course, to have a better plan.... [that] would enable us to be better prepared from a technology and a marketing perspective but also timewise. This brings new demands and requirements on information management."

With social media, the key objective of this final maturity phase is to develop reciprocal and shared engagement through jointly produced mutual beneficial outcomes in the interface. This engagement step fosters bilateral and many-to-many communication. The key social media engagement activities identified in this phase are divided into three activities: 1) full integration and KPIs, 2) integrated competence network, and 3) coproduction roadmap.

1. Full integration and KPIs: To further strengthen the social media engagement from the cooperation phase, marketing and $R \& D$ should develop full integration of engagement within the interface processes as well as with the overall business strategy. After the full integration, both functions can jointly define KPIs and engagement satisfaction criteria to assess, learn, and refine social media engagement initiatives and communities' contributions in terms of usefulness or relevance. Both functions expressed the belief that it is important to perform regular evaluations by prioritising discussion on social media engagement in both functional and cross-functional meetings.

2. Integrated competence network: After the establishment of full integration with KPIs, marketing and $R \& D$ functions built a fully integrated global competence network map related to the interface processes with the existing systems. Both functions felt that this could help to develop and run inquiry-base community networks on significant areas for joint decision-making and learning (related to the competitors or market analysis). Next, to utilize the inputs from these communities, marketing and R\&D must define a structure process to jointly discuss and channelize the opportunities to generate new product ideas and projects.

3. Coproduction roadmap: Finally, marketing and R\&D can take another step forward in their engagement in the late stages to jointly develop marketing and R\&D plans and 
roadmaps in a coproductive way. Based on the current product or service portfolios and the customer or market base, both functions can jointly discuss new opportunities and develop strategic plans and roadmaps for the short term, medium term, and long term. These coproduction efforts help marketing and $R \& D$ to give a regular feedback on each other plans, problems, and projects, establishing joint learning between the two functions. Consequently, both functions can jointly develop new concepts, prototypes, knowledge, and value-added offerings and even prepare a joint operational plan for the interface.

Based on our empirical observation and discussion with companies, these activities can achieve synchronization of development and commercialization through joint decisionmaking, development, or co-innovation efforts. Additionally, value is coproduced and jointly discovered with marketing and R\&D to learn and grow together to enhance development performance. Marketing and R\&D take an active responsibility for each other's well-being, thereby developing a deeper emotional bond and empathy. All of these efforts lead to a deeprooted content-based engagement in the interface, developing a strong tie and high degree of maturity in the engagement between marketing and R\&D. However, the expectation to jointly share sensitive or confidential information, ideas, strategic plans, and tacit knowledge between functions requires a big leap in the manner of working, calling for total reformation of processes, norms, and mindset.

Our empirical analysis revealed that, in this third phase, the social media infrastructure needs to be highly mature compared to that of phases I and II. The social media engagement shifts from providing merely active participation (i.e. 2-way engagement) to jointly working together to produce mutual beneficial outcomes in the marketing and R\&D interface. We found that mashups provide good infrastructure for coproductive social engagement; they can push ideas or requests across marketing and $R \& D$ functions with the proper use. For example, blogs or wikis can be combined with the social networking site to make continuous updates on opportunities so that interested people can easily get connected for further discussion. Furthermore, social networking sites (e.g. microblogs, Facebook, LinkedIn) build competence networks on specialized areas to discuss beta tests and prototype results. The development of online focus groups or online chat groups helps to constantly 
engage in product or service development discussions for the purpose of understanding customer needs and design rationale. In addition, wikis can be combined with video clips to further enhance the quality of the knowledge base on market information and rationale.

Overall, the three-phase adoption process ensures evolution of the engagement in a structured and systematic way, which helps marketing and R\&D to avoid early conflicts in their engagement and enhances mutual consensus with a series of step-by-step activities in the adoption of social media. With the structured adoption process, both functions can see the continuous results and benefits of their engagement. This results in further commitment from both functions, which eventually results in the establishment of a good interface coproduction between marketing and R\&D.

Table 2 summarises all key activities, infrastructure, and benefits of the three-phase adoption process of social media engagement.

\section{Discussions and Conclusions}

Prior literature highlights the importance of marketing and R\&D interface engagement in relation to achieving NPD performance (Gupta, Raj, \& Wilemon, 1985; Lam \& Chin, 2005; Li \& Chen, 2016; Song \& Song, 2010; Wiersema, 2013; Xie, Song, \& Stringfellow, 2003). However, there is limited insight into the use of social media for enhanced engagement between marketing and R\&D functions in B2B settings. Social media features demonstrate the potential to enhance interaction, collaboration, and networking between actors. The existing social media research focuses either on improving the function of R\&D (Chirumalla, 2013; Piller, Alexander, \& Christoph, 2012) or that of marketing (Moore, Hopkins, \& Raymond, 2013), but not on the interface between marketing and R\&D. Furthermore, recently, interest in the development of social media engagement strategies in industrial marketing management has increased. To address this gap, this study aims to advance the current understanding of the social media engagement strategies, which facilitates improved marketing and R\&D interfaces and ultimately NPD performance in manufacturing companies. The empirical insights provide new understanding regarding social media adoption for improved marketing and R\&D interface in B2B organizations (e.g. Jussila, Kärkkäinen, \& Aramo-Immonen, 2014; Song \& Song, 2010; Wiersema, 2013; Yao et al., 
2014). Moreover, the adoption process of social media in B2B organizations through a threephase engagement strategy, namely coordination, cooperation, and coproduction, for marketing and R\&D interface is developed and explained (e.g. Song \& Song, 2010; Wiersema, 2013; Yao et al., 2014). In sum, the findings hold important implications for research within the literatures of industrial marketing management, product innovation management, new product development, B2B social media, social media engagement, and management practice.

\subsection{Theoretical Implications}

The present study offers several theoretical implications, which provides value for industrial marketing management researchers. First, previous research acknowledged that high failure rates associated with the NPD project come as a result of poor information exchange between the marketing and R\&D interface (Hempelmann \& Engelen, 2015; Song, Neely, \& Zhao, 1996; Wiersema, 2013). Building on the role of the ICT infrastructure (e.g. Leenders \& Wierenga, 2002; Song \& Song, 2010; Yao et al., 2014) and more specifically social media perspective (Roch \& Mosconi, 2016, Christodaulides et al., 2015; Piller, Alexander, \& Christoph, 2012), this study provides insights into the critical touch points in the interface between marketing and R\&D functions. This is especially important, as previous research (Fotiadis, 2006; Moenaert et al. 1994; Micu, 2012; Song, Neeley, \& Zhao, 1996) acknowledged that formalization of interaction structures and procedures serves as an important platform to develop frequent informal interactions and information exchange. Our study directly addressed this need by identifying social media key activities and infrastructure requirements. The key detail activities in the early and late stages of development help marketing and R\&D functions to structure their interaction patterns to achieve key components required for the interface integration (Song \& Song, 2010), such as joint problem solving, relationship building, information and knowledge sharing, and collaborative communication.

Second, the empirical results advance the knowledge of perceived usefulness (Siamagka et al., 2015; Lacka \& Chong, 2016) of social media in the B2B context. The present study argues that the perceived usefulness of social media adoption depends on the 
planning and systematically organizing the social media activities. Accordingly, it is possible that the use of social media might not work or might not be fully realized when it is not positioned in the right context and utilized in the correct way. Hence, both systematic planning and a strategic adoption process are needed for the successful implementation of social media in complex industrial environments such as B2B (e.g. Guesalaga, 2016; Jussila, Kärkkäinen, \& Aramo-Immonen, 2014; Lehtimäki et al., 2009; Michaelidou, Siamagka, \& Christodoulides, 2011; Wiersema, 2013;). This study contributes to this argument by suggesting a systematic three-phase adoption process for social media engagement (i.e. coordinative engagement, cooperative engagement, and coproductive engagement) with detail activities and infrastructure requirements. This step-by-step adoption process nurtures the engagement in a more systematic way and even in a meaningful way, which could in the long run develop joint problem-solving and coproduction-building capabilities. Hence, the paper contributes to the limited theoretical area of B2B social engagement (e.g. Cawsey \& Rowley, 2016; Guesalaga, 2016; Jussila, Kärkkäinen, \& Leino, 2012; Lacoste, 2016; Rodriguez \& Peterson, 2012) by investigating and proposing a social media engagement strategy in a B2B manufacturing setting. This is in line with the previous arguments in the literature related to the requirements for successful interface integration, i.e. it requires a good rationale to engage in social media (Keinänen \& Kvivalainen, 2015), requires a formalized system of procedural interaction and the quality of the cross-functional relationship (Song, Neely, \& Zhao, 1996), and requires an informal social system and formal integrative management processes (Griffin \& Hauser, 1996).

Third, previous studies confirmed that interface integration is required both in the early and late stages of the NPD development process (Gupta, Raj, \& Wilemon, 1985) and pointed out the main facets of the maturity of interface activities (e.g. Griffin \& Hauser, 1996; Hempelmann \& Engelen, 2015; Rein, 2004). This study added the social media dimension to these activities and discussed how social media can facilitate effective information exchanges in these activities in a structured way. Furthermore, the study proposed and discussed social media infrastructure requirements in three engagement phases, which the current literature overlook. The details of social media infrastructure help companies to make the right investments and select appropriate resources to adopt social 
media tools in the interface. The study clarified the different roles and characteristics of social media in the marketing and R\&D interface. This knowledge can help companies to strategically plan and develop their capabilities to achieve effective social media engagement in the marketing and $\mathrm{R} \& \mathrm{D}$ interface.

\subsection{Limitations and future research}

This study is mainly focused on the interface between marketing and $\mathrm{R} \& \mathrm{D}$, with regard to internal social media engagement strategy. The external collaboration in the interface (e.g. between companies and customers) and differentiation between internal and external collaboration has not been considered in this study, which could influence the main results. For instance, social media engagement characteristics, phases, key activities, and infrastructure could vary between the internal and external collaboration processes. Within external companies like customers and other partners, marketing and R\&D might need to engage in even more activities to move from phases I to III (i.e. from coordinative to coproductive engagement). Future studies on the interfaces and social media engagement should consider the external dimension in their analysis. Furthermore, comparing social media engagement strategies between internal and external entities is other potential area of study in the future. This study is also explorative and relies on in-depth case study, since the current understanding of benefits of the social media engagement in the interface between marketing and $R \& D$ is limited. The empirical data was mainly derived from a multiple-case study involving two industrial companies from the manufacturing industry. Thus, the findings are context specific, so careful consideration of similar conditions is needed for the application of the adoption process and its social media engagement activities. Future studies should extend the empirical work in other large companies from other industries as well as medium-sized companies and SMEs. We welcome researchers and practitioners from other domains and industries to test the adoption process and key activities of social media engagement strategy in order to modify and update the model to suit different contexts.

Moreover, the dimension of project innovativeness or project novelty is not considered within the scope of this study. According to the previous research, the degree of interface integration between marketing and $R \& D$ interface varies based on this dimension. 
Future research should consider incremental and radical innovations (or explorative and exploitive innovations) or other related innovation category frameworks in their research in order to understand the engagement strategies, adoption process, key activities, and infrastructure of social media in B2B industrial marketing management. For instance, how could the social media engagement strategies and related activities vary from incremental to radical innovation projects interfaces?

In addition, longitudinal studies are needed in the future in order to assess and evaluate social media engagement in the marketing and R\&D interfaces, which will facilitate the collection of more quantitative data in addition to the qualitative data. Such a methodological approach could also support both deriving and testing the hypothesis based on the three-phase adoption process for the social media engagement. Future research could also extend the three-phase adoption process to business-to-consumer (B2C) situations in the industrial marketing management. Finally, the current work could also extend its focus to other critical interfaces related to marketing and R\&D interfaces in new product development such as sales or manufacturing interfaces. Streamlining all key interfaces with an efficient engagement strategy will support future new product development in achieving its goals with lower uncertainties.

\section{Acknowledgements}

The study was conducted in the context of the XPRES framework at Mälardalen University, Eskilstuna.

\section{References}

Ananda, A.S., Hernandez-Garcia, A., \& Lamberti, L. (2016). N-REL: A comprehensive framework of social media marketing strategic actions for marketing organizations. Journal of Innovation \& Knowledge, 1(3), 170-180.

Ahmad, S., Mallick, D.N., \& Schroeder, R.G. (2013). New product development: Impact of project characteristics and development practices on performance. Journal of Product Innovation Management, 30(2), 331-348.

Becker, M.C., \& Lillemark, M. (2006). Marketing/R\&D integration in the pharmaceutical industry. Research Policy, 35(1), 105-120.

Bertoni, M., \& Chirumalla, K. (2011). Leveraging Web 2.0 in new product development: 
Lessons learned from a cross-company study. Journal of Universal Computer Science, 17(4), 548-564.

Breslauer, B., \& Smith, T. (2009). Social Media trends around the world! The global web index (GWI). Online Research. Accessed on 12 September 2017:

https://2016.esomar.org/web/research_papers/Social-Networks_2044_Socialmedia-trends-around-the-world.php

Brodie, R. J., Hollebeek, L.D., Juric, B., \& Llic, A. (2011). Customer engagement: conceptual domain, fundamental propositions, and implications for research. Journal of Service Research, 14(3), 252-271.

Bughin, J., Byers, A.H., \& Chui, M. (2011). How social technologies are extending the organization. The McKinsey Quarterly. November

Bryer, T. A. (2013). Designing social media strategies for effective citizen engagement: A case example and model. National Civic Review, 102(1), 43-50.

Cawsey, T., \& Rowley, J. (2016). Social media brand building strategies in B2B companies. Marketing Intelligence \& Planning, 34(6), 754-776.

Constantinides, E., \& Fountain, S. J. (2008). Web 2.0: Conceptual foundations and marketing issues. Journal of Direct, Data and Digital Marketing Practice, 9(3), 231-244.

Chirumalla, K. (2013). Managing knowledge for product-service system innovation: The role of Web 2.0 technologies. Research-Technology Management, 56(2), 45-53.

Chirumalla, K. (2016). Organizing lessons learned practice for product-service innovation. Journal of Business Research, 69(11), 4986-4991.

Eng, T-Y., \& Ozdemir, S. (2014). International R\&D partnerships and intrafirm R\&Dmarketing-production integration of manufacturing firms in emerging economies. Industrial Marketing Management, 43(1), 32-44.

Eriksson, P., \& Kovalainen, A. (2008). Qualitative methods in business research, London, UK: SAGE Publications Ltd.

Eisenhardt, K. M., \& Graebner, M. E. (2007). Theory building from cases: Opportunities and challenges. Academy of Management Journal, 50(1), 25-32.

Fain, N., Kline, M., \& Duhovnik, J. (2011). Integrating R\&D and marketing in new product development. Strojniški vestnik-Journal of Mechanical Engineering, 57(7-8), 599609.

Fain, N., \& Wagner, B. (2014). R\&D-marketing integration in innovation - does culture matter? European Business Review, 26(2), 169-187

Fotiadis, T. (2006). Integration of marketing and R\&D in high-tech enterprises: concept significance - barriers. The Cyprus Journal of Sciences, 4, 129-144.

Geroski, P.A., \& Machin S. (1992). Do Innovating Firms Outperform Non-innovators? Business Strategy Review, 3(2), 79-90.

Gomes, J.F.S., de Weerd-Nederhof, P.C., Pearson, A.W., \& Cunha, M.P. (2003). Is more 
always better? An exploration of the differential effects functional integration on performance in new product development. Technovation, 23(3),185-191.

Guesalaga, R. (2016). The use of social media in sales: Individual and organizational antecedents, and the role of customer engagement in social media. Industrial Marketing Management, 54, 71-79.

Gupta, A.K., Raj, S.P., \& Wilemon, D., (1985). The R\&D-marketing interface in hightechnology firms. Journal of Product Innovation Management, 2(1), 12-24.

Gupta, A.K., \& Wilemon, D. (1988). The Credibility - Cooperation connection at the R\&DMarketing interface. Journal of Product Innovation Management, 5(1), 20-31.

Griffin, A., \& Hauser, J.R. (1996). Integrating R\&D and marketing: a review and analysis of the literature. Journal of Product Innovation Management, 13(3), 191-215.

Hempelmann, F., \& Engelen, A. (2015). Integration of finance with marketing and R\&D in new product development: The role of project stage. Journal of Product Innovation Management, 32(4), 636-654.

Hernandez, A., \& Lee, J.S. (2007). A comprehensive model of conflict at the R\&D/Marketing Interface: Linking organizational factors and conflict to new product performance. Proceedings: PICMET, 5-9 August, USA.

Huang, J. J. S., Yang, S. J., H., Huang, Y. M., \& Hsiao, I. Y. T. (2010). Social learning networks: build mobile learning networks based on collaborative services. Educational Technology \& Society, 13(3), 78-92.

Jussila, J.J., Kärkkäinen, H., \& Leino, M. (2012). Social media's opportunities in businessto-business customer interaction in innovation process. International Journal of Technology Marketing, 7(2), 191-208.

Jussila, J. J., Kärkkäinen, H., \& Aramo-Immonen, H. (2014). Social media utilization in business-to-business relationships of technology industry firms. Computers in Human Behavior, 30, 606-613.

Jassawalla, A.R., \& Sashittal, H.C. (1997). An Examination of Collaboration in HighTechnology New Product Development Processes. Journal of Product Innovation Management, 15(3), 237-254

Kaplan, A.M., \& Haenlein, M. (2010). Users of the world, unite! The challenges and opportunities of social media. Business Horizons, 53(1), 59-68.

Kumar, V.B. (2013). Improving the success rate of new product introduction through digital social media. Accessed on 27 August on PDMA.org. http://www.pdma.org/p/bl/et/blogaid=115

Kvale. S. (1996). Interviews: An Introduction to Qualitative Research Interviewing. Thousand Oaks, CA: Sage Publications.

Keinänen, H., \& Kvivalainen, O. (2015). Antecedents of social media B2B use in industrial marketing context: customer's view. Journal of Business \& Industrial Marketing, 30(6), 711-722. 
Kietzmann, J.H., Hermkens, K., McCarthy, I.P., \& Silvestre, B.S. (2011). Social media? Get serious! Understanding the functional building blocks of social media. Business Horizons, 54(3), 241-251.

Kärkkäinen, H., Jussila, J., \& Janhonen, J. (2011). Managing customer information and knowledge with social media in business-to-business companies, in: Proceedings of the 11th International Conference on Knowledge Management and Knowledge Technologies. Graz, Austria, 7-9 September.

Lam, P.-K., \& Chin, K.-S. (2005). Identifying and prioritizing critical success factors for conflict management in collaborative new product development. Industrial Marketing Management, 34(8), 761-772.

Lofland, J., Snow, D.A., Anderson, L., \& Lofland, L.H. (2005). Analyzing social settings: A guide to qualitative observation and analysis. Belmont, CA: Cengage Learning.

Leenders, M.A.A.M., \& Wierenga, B. (2008). The effect of the Marketing-R\&D interface on new product performance: The critical role of resources and scope. International Journal of Research in Marketing, 25(1), 56-68.

Leenders, M.A.A.M., \& Wierenga, B. (2002). The effectiveness of different mechanisms for integrating marketing and R\&D. Journal of Product Innovation Management, 19(4), 305-317.

Lacka, E., \& Chong, A. (2016). Usability perspective on social media sites' adoption in the B2B context. Industrial Marketing Management, 54, 80-91.

Lacoste, S. (2016). Perspectives on social media and its use by key account managers. Industrial Marketing Management, 54, April, 33-43.

Lau, E. K. W. (2015). Understanding a company's social media strategies and customer engagement. L. Uden et al. (Eds.): KMO 2015, LNBIP 224, 438-450.

Li, P-C., \& Chen, Y-C. (2016). Exploring interaction-based antecedents of marketing-R\&D collaboration: evidence from the Taiwan's semiconductor industry. Journal of Innovation: Organization \& Management, 18(3), 352-372.

Lu, L.Y.Y., \& Yang, C. (2004). The R\&D and marketing cooperation across new product development stages: An empirical study of Taiwan's IT study. Industrial Marketing Management, 33(7), 593-605.

Lehtimäki, T., Salo, J., Hiltula, H., \& Lankinen, M. (2009). Harnessing web 2.0 for business to business marketing - Literature review and an empirical perspective from Finland. Oulu University Press.

Mack, N., Woodsong, C., MacQueen, K.M., Guest, G., \& Namey, E. (2005). Qualitative research methods: A data collector's field guide. NC: Family Health International.

Musser, J., \& O'Reilly, T. (2006). Web 2.0 principles and Best practices. O'Reilly Radar report.

Michaelidou, N. Siamagka, N., \& Christodoulides, G. (2011). Usage, barriers and measurement of social media marketing: An exploratory investigation of small and 
medium B2B brands. Industrial Marketing Management, 40(7), 1153-1159

Miles, M.B., \& Huberman, A.M. (1994). Qualitative Data Analysis: An Expanded Sourcebook. CA: Sage Publications.

Micu, D., Ifrim, L., Daraban, C., \& Purdescu, C. (2012). Cross-functional linkages between marketing and the other business functions in an industrial organization. U.P.B. Sci. Bull., Series D, 74(3), 241-252.

Moore, J.N., Hopkins, C.D., \& Raymond, M.A. (2013). Utilization of Relationship-Oriented Social Media in the Selling Process: A Comparison of Consumer (B2C) and Industrial (B2B) Salespeople. Journal of Internet Commerce, 12(1), 48-75.

Moenaert, R.K., Souder, W.E., De Meyer, A.D., \& Deschoolmeester, D. (1994). R\&DMarketing integration mechanisms, communication flows, and Innovation success. Journal of Product Innovation Management, 11(1), 31-45.

Marcos-Cuevas, J., Nätti, S., Palo, T., \& Baumann, J. (2016). Value co-creation practices and capabilities: Sustained purposeful engagement across B2B systems. Industrial Marketing Management, 56, 97-107.

Olson. E.M., Walker, O.C., Ruekert, R.W., \& Bonner, J.M. (2001). Patterns of cooperation during new product development among marketing, operations and R\&D: Implications for project performance. Journal of Product Innovation Management, $18(4), 258-71$.

Patton. M. Q. (2002). Qualitative Research \& Evaluation Methods. CA: Sage Publications.

Petruska, I. (2004). R\&D-Marketing integration in the new product development process. Periodica Polytechnica Ser. Soc. Man. Scl, 12(2), 159-176.

Piller, F.T., Alexander, V., Christoph, I. (2012). From social media to social product development: The impact of social media on co-creation of innovation. Die Unternehmung, 65(1), December.

Rein, G.L. (2004). From Experience: Creating synergy between marketing and research and development. The Journal of Product Innovation Management, 21(1), 33-43.

Roch, J., \& Mosconi, E. (2016). The use of social media tools in the product life cycle phases: A systematic literature review. $49^{\text {th }}$ Hawaii International Conference on System Sciences.

Rodriguez, M., Peterson, R. M., \& Krishnan, V. (2012). Social Media's Influence on Business-to-Business Sales Performance. Journal of Personal Selling and Sales Management, 32(3), 365-378.

Rodriguez, M., \& Peterson, R. M. (2012). The role of social CRM and its potential impact on lead generation in business-to-business marketing. International Journal of Internet Marketing and Advertising, 7(2), 180-193.

Rohmann, S., Heuschneider, S., \& Schumann, M. (2014). Social software in new product development - State of research and future research directions. $20^{\text {th }}$ Americas Conference on Information Systems, Savannah. 
Scherp A., Schwagereit F., \& Ireson T. (2009). Web 2.0 and traditional knowledge management processes, In Proc. Int. Workshop on Knowledge Services \& Mashups.

Saghafi, M.M., Gupta, A., \& Sheth, J.N. (1990). R\&D/Marketing interfaces in the Telecommunications industry. Industrial Marketing Management, 19(1), 87-94.

Spil, T. A. M., Effing, R., \& Both, M.P. (2016). Enable, Engage and Evaluate: Introducing the $3 \mathrm{E}$ Social Media Strategy Canvas Based on the European Airline Industry. Dwivedi, Y.K. et al. (Ed.,): Social Media: The Good, the Bad, and the Ugly. pp.15-30.

Song, L.Z., \& Song, M. (2010). The Role of Information Technologies in Enhancing R\&DMarketing Integration: An Empirical Investigation. Journal of Product Innovation Management, 27(3), 382-401.

Song, X. M., Neeley, S. M., \& Zhao, Y. (1996). Managing R\&D-Marketing Integration in the New Product Development Process, Industrial Marketing Management, 25(6), 545-553.

Siamagka, N.T, Christodoulides, G., Michaelidou, N., \& Valvi, A. (2015). Determinants of Social Media Adoption by B2B Organizations. Industrial Marketing Management, 51, November, 89-99.

Stelzner, M. A. (2014). Social media marketing industry report. How Marketers Are Using Social Media to Grow Their Businesses. Accessed on April $20^{\text {th }}$ http://www.socialmediaexaminer.com/SocialMediaMarketingIndustryReport2 014.pdf

Voigt, K.-I., \& Ernst, M. (2010). Use of Web 2.0 applications in product development: an empirical study of the potential for knowledge creation and exchange in research and development. International Journal of Engineering, Science and Technology, 2(9), 54-68.

Vuori, M. (2012). Exploring uses of social media in a global corporation. Journal of Systems and Information Technology, 14(2), 155-170.

Wang, Q. (1996). The exploitation of a multidisciplinary approach in studying the $\mathrm{R} \& \mathrm{D} /$ marketing with some empirical evidence. International Journal of Technology Management, 11(3-4), 369-379.

Wiersema, F. (2013). The B2B agenda: The current state of B2B marketing and a look ahead. Industrial Marketing Management, 42(4), 470-488.

Xie, J., Song, X.M., \& Stringfellow, A. (2003). Antecedents and consequences of goal incongruity on new product development in five countries: a marketing view. Journal of Product Innovation Management, 20(3), 233-250.

Yin, R.K. (2009). Case study research: Design and methods. Thousand Oaks, CA: Sage Publications.

Yao, Q., Xu, M., Song, H., Jiang, W., \& Zhang, Y. (2014). R\&D-Marketing integration and 
performance-Evidence provided by agricultural science and technology enterprises. Journal of Service Science and Management, 7, 18-29. 